DOI: https://doi.org/10.47405/mjssh.v6i9.998

\begin{tabular}{|c|c|}
\hline 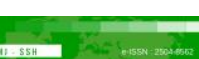 & Malaysian Journal of Social Sciences and Humanities (MJSSH) \\
\hline Malaysian Journal of & Volume 6, Issue 9, September 2021 \\
\hline (MJ-ssH) & e-ISSN : 2504-8562 \\
\hline & $\begin{array}{l}\text { Journal home page: } \\
\text { www.msocialsciences.com }\end{array}$ \\
\hline
\end{tabular}

\title{
Contributing Factors to Decline in Physical Activity Among Adolescents: A Scoping Review
}

\author{
Normawati Ahmad1, Hasnor Hadi Asim², Nurashma Juatan1, Nor Ezra Hipni², Nurbaidurrah Ithnain1, \\ Nor Haryati Ahmad Sanusi', Siti Nur Farhana Harun', Muhammad Ridzwan Zakaria1, Norrafizah \\ Jaafar $^{1}$, Mohd Haazik Mohamed ${ }^{4}$, Siti Hajar Suraji ${ }^{5}$, Manimaran Krishnan ${ }^{1}$ \\ ${ }^{1}$ Institute for Health Behavioural Research, National Institutes of Health, Ministry of Health Malaysia \\ ${ }^{2}$ Melaka State Health Department, Ministry of Health Malaysia \\ ${ }^{3}$ Sibu Hospital, Sarawak, Ministry of Health Malaysia \\ ${ }^{4}$ Universiti Malaysia Sabah (UMS), Malaysia \\ 5Tengku Ampuan Rahimah Hospital, Klang, Ministry of Health Malaysia \\ Corresponding author: Normawati Ahmad (yejinnor@gmail.com)
}

\begin{abstract}
It is presumed that the level of physical activity (PA) declines during a person's lifespan, particularly during adolescence. The main objective of this scoping review is to summarize and identify the current literature that addresses contributing factors related to adolescent physical inactivity. This scoping review was carried out using the framework suggested by Arskey and O'Malley. The literature review was undertaken using the reference period between 2008 and 2014, based primarily on the PubMed, Cochrane and Embase databases. Additional studies have been identified by a manual bibliography search. Search term included adolescent / youth / teenage, factors / determinants /correlations, and physical inactivity/decline exercise. A total of 23 studies met the inclusion criteria. This scoping review found some evidence of the association between physical inactivity and the following variables: Age, sex, socio-economic status, lack of social support from parents, family and friends have had an impact on their motivation to perform PA on a continuous basis. Also, the lack of awareness, attitudes, and practices of individuals themselves for not doing PA has affected their interest in maintaining PA. It is noted that the environment also plays an important role, such as inadequate facilities and facilities, as well as an unsuitable place or setting that is unconducive and a neighbourhood that does not take care of or is aware of a healthy lifestyle, is also a contributing factor to physical inactivity. The decline in PA during adolescence is a consistent finding in the literature. However, PA interventions should be developed through education, family programs, behavioural or environmental and policy changes.
\end{abstract}

Keywords: decline, physical activity, adolescents

\section{Introduction}

Regular physical activity has been shown to help prevent and manage non-communicable diseases (NCDs) such as heart disease, stroke, diabetes and several cancers. It also helps prevent hypertension, maintains healthy body weight and can improve mental health, quality of life and well-being. Physical activity refers to all movements. Popular ways to be active include walking, cycling, wheeling, sports, active recreation and play, and can be done at any level of skill and enjoyment by everybody. 
However, current global estimates show that one in four adults and $81 \%$ of adolescents do not have enough physical activity. Moreover, as countries develop economically, levels of inactivity increase and may be as high as $70 \%$ due to changing transport patterns, increased use of technology for work and recreation, cultural values and increased sedentary behaviour. Increased levels of physical inactivity have a negative impact on health systems, the environment, economic development, community well-being and quality of life (https://www.who.int/health-topics/physical-activity\#tab=tab_1).

Physical inactivity (PI) has been identified as one of the biggest public health problems of the $21 \mathrm{st}$ century (Dumith et al. 2011). Globally, around 31\% of adults aged 15 and above were insufficiently active in 2008 (men 28\% and women 34\%). Approximately 3.2 million deaths each year are attributable to insufficient physical activity (WHO 2008). Approximately three to four adolescents between 11 to 17 years of age have been reported to have failed to comply with the WHO's recommended physical activity guideline (UN-habitat 2013).

A study conducted among New Zealand adolescents has also shown that a greater reduction in PI occurs at a time when their secondary school education is too incomplete and the decision to move to a tertiary institution and employment is taken (McLean, 2004). Lack of motivation, social distraction, academic stress, harsh environmental weather was among the reasons for PI reported by university students (Gyurcsik, Bray \& Brittain 2004).

The health benefits of PA are widely demonstrated by recent scientific literature. There is strong evidence that regular PA improves body composition, cardiorespiratory and muscular fitness, bone health and metabolic health biomarkers among children and adolescents (USDA 2008). In addition, youth PA can have both direct and indirect positive effects on adult health (Telama et al. 2005) and track from adolescence to adulthood, suggesting that PA promotion must start early in life (Hallal et al. 2006).

In Malaysia, the decline in PA during adolescence is a key public health concern because it is related to increase in the prevalence of obesity. The National Health Morbidity Survey (NHMS) 2011 shows that the prevalence of obesity in Malaysia increased from 4.4\% in NHMS 1996 to $15.1 \%$ (2.5 million). Obesity among adolescence is about 19.6\% (NHMS 2011). The NHMS report (2006 \& 2011) shows that only $64.3 \%$ of the population of Malaysia is active. Sedentary lifestyles among Malaysians can contribute to an increase in the prevalence of obesity and have been identified as a key risk factor for cardiovascular disease. Similarly, in a study conducted by Reilly (2005) and Taras and Datema (2005), despite full knowledge and awareness of the benefits of regular PA, the number of PI adolescents increased, leading to an increase in childhood obesity. Childhood obesity not only increases the risk of health-related consequences but can negatively affect self-esteem and contribute to student absenteeism and reduced school learning.

According to the 2008 PA Guidelines, which complement the Dietary Guidelines for Americans, children and adolescents should do 60 minutes or more of PA daily, such as aerobic, bone-strengthening and muscle-strengthening (PA Guidelines Advisory Committee Report 2008). While in Malaysia, a 30 minute or more PA should be done every day. In addition, sedentary activities must be limited to a maximum of two hours or less per day. For example, watching TV, playing video games, surfing the Internet and sitting or lying down (with the exception of sleeping) (Malaysian Dietary Guidelines 2010).

From the expected finding, we aim to understand the factors that contribute to the decline of PA among adolescents, and thus hope that appropriate intervention programs for adolescents, the health of future generations, can be developed.

\section{Objective}

i. To identify interpersonal factors that contribute to the decline in PA among adolescents.

ii. To identify the environmental factors that contribute to the decline of PA among adolescents.

\section{Definition}




\section{Decline (Physical Inactivity)}

Physical Inactivity or what some called insufficiently active or was defined as "doing some physical activity but less than 150 minutes of moderate-intensity physical activity or 60 minutes of vigorousintensity physical activity a week accumulated across work, home, transport or discretionary domains" (Bull et al. 2004)

\section{Adolescence}

Transitional phase of growth and development between childhood and adulthood. The World Health Organization (WHO) defines an adolescent as any person between ages 10 and 19 years old. (WHO 2014).

\section{Methodology}

\section{Design Scoping Review}

The review follows the scoping methodology outlined by Arksey and O'Malley (2005). Consistent with this methodology, the review was conducted in 5 steps. Step 1 involved developing the research questions; Step 2 identifying relevant studies; Step 3 selecting studies; Step 4 charting data; and Step 5 collating, summarizing and reporting results. A project team consisting of health education officers, policymakers and researchers was established to develop the research question and oversee the study.

\section{Step 1: Identifying the research questions}

The review questions were:

i. What are the environmental factors that contribute to the decline of PA among adolescents?

ii. What are the interpersonal factors that contribute to the decline of PA?

\section{Step 2: Identifying relevant studies}

\section{Search Term}

Key terms were selected to locate studies pertinent to the research questions outlined. The search terms used were as follows: [Decline OR Inactive OR Inaction] for PI, [Youth OR Teenage OR Youngster] for Adolescent, and [Associate OR Related OR Cause] for Contribute. The search terms were entered into the databases with an "and" term between each of them.

Explicit inclusion criteria were used to ensure that all relevant studies were reviewed. Studies were included if they met the following criteria: (a) subjects were 10-19 years old; (b) published between 2008 till 2014; (c) contributed factors, and determinants of PA; (e) research reported in Malay and English.

\section{Database}

Five databases were utilized in this review based on topic area: PubMed, Cochrane and Embase. The researchers believed these three (3) search databases would reach all the relevant journals within the area of interest. Overall, 23,528 articles were found using the above search terms and databases. 


\section{Step 3: Study selection}

We conducted a scoping review using the Preferred Reporting Items for Systematic Meta-Analysis extension for scoping review (PRISMA-ScR) (PRISMA; Liberati, Tetzlaff, Altman, \& Group, 2009). Figure 1 depicts the study selection process. The initial selection criteria were broad to ensure that as many studies as possible are assessed as to their relevance to the review. Any articles that irrelevant were excluded in the early stages of the search, whilst the decision to exclude or include the articles were only be made once the articles had been sorted systematically. Endnote software and Microsoft Excel programs were used to manage the records and sorting reference lists. The researchers then compiled these records and made a summary.

Figure 1: PRISMA flow diagram on selection process
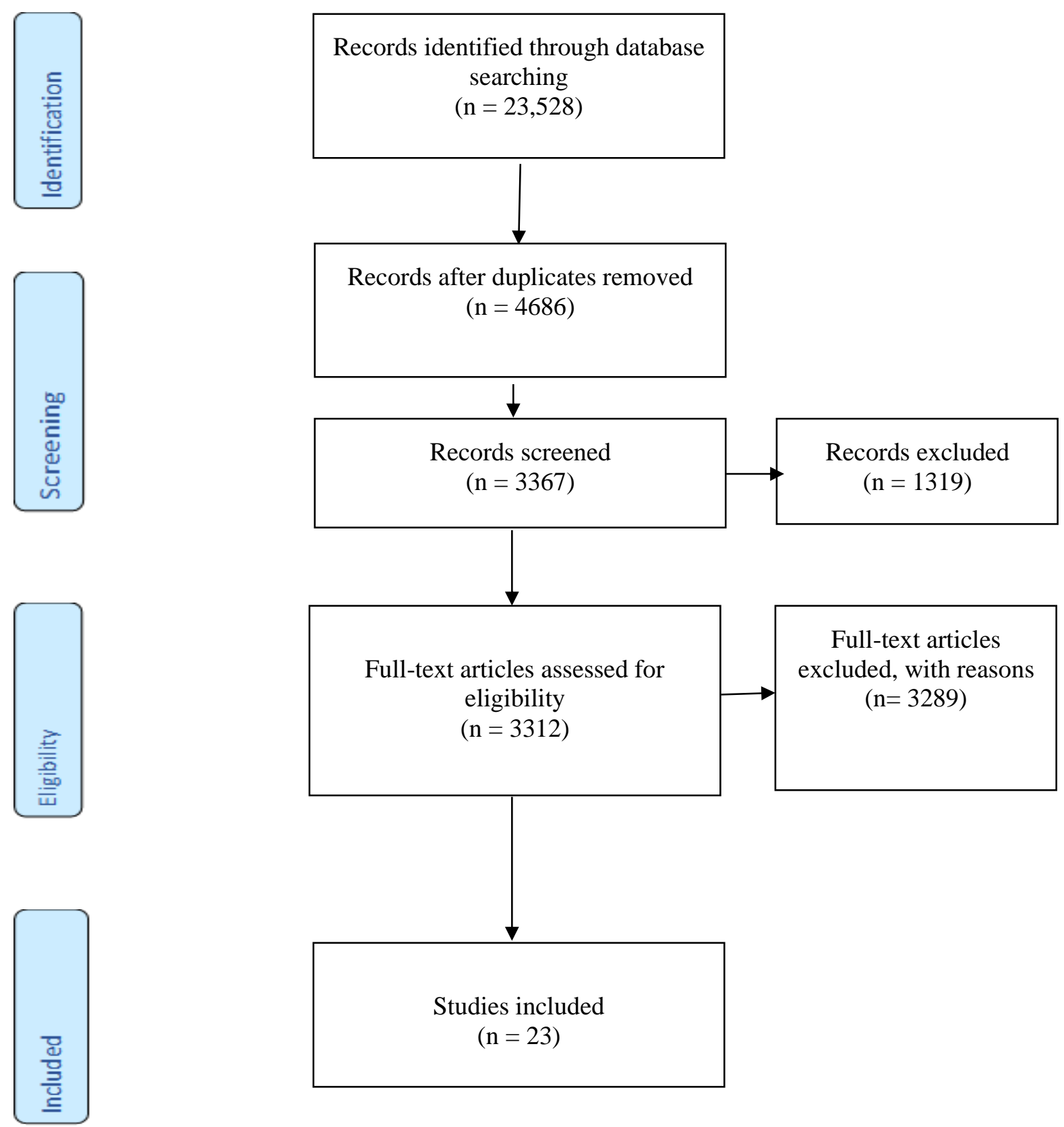


\section{Step 4: Chart the Data}

Data were summarized systematically and extracted to format in a form of table. The collected data points were author(s), title, publication year, research methods, participant's sample size and findings.

\section{Step 5: Collate, Summarize and Report Results}

The last stage of the Arksey and O'Malley (2005) framework was to organize the relevant findings into themes, prioritizing the results based on relevance to the research questions. All data have been reported in the results section below. The main focus of our scoping review was to summarize the range of evidence and identify any gaps in the literature. We summarized and reported on the factors that contribute to physical inactivity among adolescents.

\section{Results}

A total of 23,528 titles were extracted from an electronic database and other resources shown in Figure 1. About 3367 abstracts were included after the initial screening process and the rest were excluded as they were irrelevant with regards to the decline of PA, non-English articles, and duplicates. Only 23 studies met the inclusion criteria. Summary articles are included in Table 1.

Of these 23 studies, 10 articles were studies among adolescents with environmental factors, 8 articles were studies on interpersonal factors, and 5 articles were studied with both interpersonal and environmental factors. Countries of original studies included such as the United Kingdom, USA, Canada, Australia, China, Germany, Iran, Scotland, Portugal, Slovakia, Spain and Malaysia. The majority of the studies (13) were cross-sectional studies, while the rest used longitudinal studies (2), qualitative studies (3). Only one for each Randomized Control Trial study (RCT), Cohort study, mix-method study, telephone survey and Lab study was included in this review.

The sample size of the studies ranged from 100 to 60000 adolescents aged 10-19 years old. The study population was recruited from various sources which included public schools, private schools, colleges, and households (parents). 
Table 1: Summary Articles Included

\begin{tabular}{|c|c|c|c|c|}
\hline No. & Author/Year & Study Design & Participants & Findings \\
\hline 1. & $\begin{array}{l}\text { Lammle, Worth, } \\
\& \text { Bos, (2012) }\end{array}$ & $\begin{array}{l}\text { A cross-sectional survey } \\
\text { (German) }\end{array}$ & 2574 respondents & $\begin{array}{l}\text { - Results revealed that immigrant children with a lower SES background was less physically } \\
\text { active. }\end{array}$ \\
\hline 2. & $\begin{array}{l}\text { Taymoori, Berry, } \\
\& \text { Lubans (2012) }\end{array}$ & $\begin{array}{l}\text { Longitudinal study } \\
\text { (Iran) }\end{array}$ & 1073 respondents & $\begin{array}{l}\text { - The girls were less active than boys at both time points. Girls reported lower self-efficacy } \\
\text { and perceived more barriers and fewer perceived benefits for physical activity over time. } \\
\text { - Interpersonal influences on activity were more stable for girls than boys. }\end{array}$ \\
\hline 3. & $\begin{array}{l}\text { Cooper, A. R. et } \\
\text { al. } \\
(2012)\end{array}$ & $\begin{array}{l}\text { A cross-sectional survey } \\
\text { (United Kingdom) }\end{array}$ & 1307 respondents & $\begin{array}{l}\text { - Change from active to passive transportation to school may contribute to the decline in } \\
\text { physical activity seen between primary and secondary school. }\end{array}$ \\
\hline 4. & $\begin{array}{l}\text { Dudley, D. A } \\
\text { (2012) }\end{array}$ & $\begin{array}{l}\text { Observation } \\
\text { (Australia) }\end{array}$ & 81 respondents & $\begin{array}{l}\text { - Time spent in vigorous physical activity during PE was observed. } \\
\text { - The results shown, there was no significant decline in moderate-to-vigorous physical } \\
\text { activity. }\end{array}$ \\
\hline 5. & $\begin{array}{l}\text { Bradley et al. } \\
(2011)\end{array}$ & $\begin{array}{l}\text { Longitudinal Study } \\
\text { (USA) }\end{array}$ & 801 participants & $\begin{array}{l}\text { - The minutes of moderate to vigorous PA per day declined dramatically from age } 9 \text { to age } \\
15 \text { years for both boys and girls. }\end{array}$ \\
\hline 6. & $\begin{array}{l}\text { Wilson et al. } \\
(2012)\end{array}$ - & $\begin{array}{l}\text { Randomised Control Trial } \\
\text { (USA) }\end{array}$ & $\begin{array}{l}280 \text { parents of youth } \\
\text { took part in the study. }\end{array}$ & $\begin{array}{l}\text { - Indicated a significant effect of parental and neighbourhood supports for physical activity } \\
\text { on adolescent MVPA. } \\
\text { - Adolescent who perceived higher (vs lower) levels of parental support for physical activity } \\
\text { engaged more minutes of MVPA. } \\
\text { - Adolescent who lived in neighbourhood with more (vs fewer) supports for physical activity } \\
\text { (parks, lighting) also engaged in more minutes MVPA. } \\
\text { - Support from parents and neighborhood quality are both associated with increased physical } \\
\text { activity in underserved adolescents. }\end{array}$ \\
\hline
\end{tabular}




\begin{tabular}{|c|c|c|c|c|}
\hline No. & Author/Year & Study Design & Participants & Findings \\
\hline 7. & $\begin{array}{lr}\text { Chen } & \text { You, } \\
\text { Zhonghui Zheng, } \\
\text { Jinyao Yi \& } \\
\text { Shuqiao Yao } \\
(2014)\end{array}$ & $\begin{array}{l}\text { A cross-sectional study } \\
\text { (China) }\end{array}$ & 9,901 students, & $\begin{array}{l}\text { - Academic pressure to prepare for the national college entrance examination may be a } \\
\text { significant driving force in sedentary behavior. } \\
\text { - Age is a contributor, as previous studies showed that there existed an age related decline in } \\
\text { physical activity in students } \\
\text { - The probability of physical inactivity significantly increased with grade and decreased with } \\
\text { socioeconomic status. }\end{array}$ \\
\hline 8. & $\begin{array}{l}\text { Hylok, } \\
(2011)\end{array}$ & $\begin{array}{l}\text { A cross sectional study } \\
\text { (USA) }\end{array}$ & 208 respondents & - Physical activity does not have a significant relationship with academic achievement. \\
\hline 9. & $\begin{array}{l}\text { Jaroslava } \\
\text { Kopcakova et.al. } \\
\text { (2014) }\end{array}$ & $\begin{array}{l}\text { A cross sectional study } \\
\text { (Slovakia) }\end{array}$ & 8042 adolescents & $\begin{array}{l}\text { - This study revealed that adolescents with a negative body image engage in irregular } \\
\text { sufficient physical activity less often than others } \\
\text { - boys are prone to be physically inactive when they are dissatisfied with their body image. }\end{array}$ \\
\hline 10. & $\begin{array}{l}\text { Sawka et al. } \\
(2014)\end{array}$ & $\begin{array}{l}\text { A cross-sectional study } \\
\text { (Canada) }\end{array}$ & 1061 respondents & $\begin{array}{l}\text { - There was a sign interaction between the proportion of sedentary close friends and general } \\
\text { perceived support from friends in relation to being sufficiently active. } \\
\text { - There was a significant interaction between general perceived social support from friends } \\
\text { and clique membership and a decreased likelihood of being highly sedentary. } \\
\text { - Adolescent who received no friendship nominations spent significantly fewer days per week } \\
\text { participating in } 60 \text { minutes of MVPA compared with adolescent who received at least one } \\
\text { friendship nomination. }\end{array}$ \\
\hline
\end{tabular}




\begin{tabular}{|c|c|c|c|c|}
\hline No. & Author/Year & Study Design & Participants & Findings \\
\hline 11. & $\begin{array}{l}\text { Bélanger et al. } \\
\text { 2011) }\end{array}$ & $\begin{array}{l}\text { Qualitative Study } \\
\text { (Canada) }\end{array}$ & 1255 students & $\begin{array}{l}\text { Theme 2: Social support and pressure } \\
\text { Decliner : } \\
\text { - No support from parent } \\
\text { - Social environment } \\
\text { Theme 4: Perceived competence } \\
\text { Decliner : } \\
\text { - } \quad \text { Compare themselves to peers and negatively evaluate their skill levels } \\
\text { - } \quad \text { Bevaluate skills and lead them to stop continue their PA } \\
\text { Theme 5: Access } \\
\text { Decliner : } \\
\text { - } \quad \text { Difficulties to get access to activities they liked } \\
\text { Access to competitive sports becomes reserved to the most athletically inclined } \\
\text { - Cost of registration and equipment } \\
\text { Time constraints }\end{array}$ \\
\hline 12. & $\begin{array}{l}\text { Babey, et al. } \\
(2008)\end{array}$ & $\begin{array}{l}\text { Telephone Survey } \\
\text { (USA) }\end{array}$ & 4010 respondents & $\begin{array}{l}\text { Adolescents without access to a safe park were among those living in: } \\
\text { (1) apartment buildings, } \\
\text { (2) unsafe neighbourhoods, and } \\
\text { (3) lower income families. }\end{array}$ \\
\hline 13. & $\begin{array}{l}\text { Kirby, J., Levin, } \\
\text { K.A. \& Inchley, J. } \\
2013\end{array}$ & Qualitative study & FGDs $(n=63)$ & $\begin{array}{l}\text { - From lower income family } \\
\text { - Parental safety concerns: with some parents not allowing their children to go out by } \\
\text { themselves. } \\
\text { - Parents were also reported as discouraging sedentary behaviour within the home }\end{array}$ \\
\hline 14. & $\begin{array}{l}\text { Kwan } \\
(2012)\end{array}$ et al. & A cross-sectional survey & 640 respondents & $\begin{array}{l}\text { - Physical activity decline was evident during young adults' transition into early adulthood, } \\
\text { with declines being steepest among men who entered a college/university. } \\
\text { - Although there were increases in several health-risk behaviors during adolescence, individuals } \\
\text { tend to grow out of binge drinking and smoking as they mature. }\end{array}$ \\
\hline
\end{tabular}




\begin{tabular}{|c|c|c|c|c|}
\hline No. & Author/Year & Study Design & Participants & Findings \\
\hline 15. & $\begin{array}{l}\text { Serrano-Sanchez } \\
\text { JA, Martí-Trujillo } \\
\text { S, Lera-Navarro } \\
\text { A: } 2011 \text {, }\end{array}$ & $\begin{array}{l}\text { A cross-sectional study. } \\
\text { A multi-stage stratified } \\
\text { random sampling method } \\
\text { (Spain) }\end{array}$ & 3503 adolescents & $\begin{array}{l}\text { Adolescents are particularly } \\
\text { likely to prefer television viewing and computer usage, commonly called "screen time", because } \\
\text { they consider these activities to be more entertaining than physical activity. }\end{array}$ \\
\hline 16. & $\begin{array}{l}\text { Charlton et al. } \\
\text { (2014) }\end{array}$ & $\begin{array}{l}\text { Mix method study } \\
\text { (UK) }\end{array}$ & 1147 children & $\begin{array}{l}\text { a. Quantitative findings: } \\
\text { Reasons for Physical In activity: } \\
\text { Deprived, female, have obesity in the family and not achieve in } \\
\text { education }\end{array}$ \\
\hline & & & & $\begin{array}{l}\text { b. Qualitative Findings: } \\
\text { Showed barriers to physical activity include cost, poor access to activity, lack of core physical } \\
\text { literacy skills and limited family support. }\end{array}$ \\
\hline 17. & $\begin{array}{l}\text { Marques, A \& } \\
\text { Gaspar de Matos, } \\
\text { M. (2014). }\end{array}$ & $\begin{array}{l}\text { A Cohort Study } \\
\text { (Portugal) }\end{array}$ & $\begin{array}{l}8483 \text { adolescents } \\
(4067 \text { boys, } 4416 \\
\text { girls) }\end{array}$ & $\begin{array}{l}\text { - The prevalence of physical inactivity increased significantly among boys between ages } \\
\text { - The number of times adolescents practised PA during the past } 7 \text { days remained relatively } \\
\text { stable, which means that the campaigns and attempts to increase PA among adolescents } \\
\text { have not been very successful. } \\
\text { - With age, there was a significant decrease in most sports activities among boys and girls. } \\
\text { This indicated that as adolescents are getting older, they may have different interests } \\
\text { leading some to stop practising PA. }\end{array}$ \\
\hline 18. & $\begin{array}{l}\text { Graham et. al } \\
(2011)\end{array}$ & $\begin{array}{l}\text { A laboratory based Study } \\
\text { (USA) }\end{array}$ & 192 respondents & $\begin{array}{l}\text { Decliner: } \\
\text { - Low environmental resources } \\
\text { - No social support from parents \& friends } \\
\text { - Not competence to do exercise. }\end{array}$ \\
\hline
\end{tabular}




\begin{tabular}{|c|c|c|c|c|}
\hline No. & Author/Year & Study Design & Participants & Findings \\
\hline 19. & $\begin{array}{l}\text { Hsu Y.Wen et al. } \\
(2011)\end{array}$ & $\begin{array}{l}\text { A cross-sectional study } \\
\text { (USA) }\end{array}$ & 666 respondents & $\begin{array}{l}\text { Decliner: } \\
\text { 1. Internal barrier: } \\
\text { - Lack self-discipline or will power (lack self-discipline/will power) } \\
\text { - Long-term illness, disability, or injury (illness/disability/injury) } \\
\text { Feeling stressed (stressed) } \\
\text { 2. External barrier } \\
\text { - Lack of support from family } \\
\text { - Lack of support from friends } \\
\text { - Lack of time due to family responsibility. }\end{array}$ \\
\hline 20. & $\begin{array}{l}\text { Cheah et al. } \\
(2014)\end{array}$ & $\begin{array}{l}\text { A cross-sectional survey } \\
\text { (Malaysia) }\end{array}$ & 145 respondents & $\begin{array}{l}\text { - } 27 \% \text { of the respondents were either overweight or obese, with more females in this group } \\
\text { - PA level was low and almost one-third of the respondents were overweight and obese. } \\
\text { - Female students faced more barriers and had lower self-efficacy with regards PA. }\end{array}$ \\
\hline 21. & $\begin{array}{l}\text { Chung et al. } \\
(2012)\end{array}$ & $\begin{array}{l}\text { A cross-sectional survey } \\
\text { (USA) }\end{array}$ & Not reported & $\begin{array}{l}\text { - Boys were more active than girls, and activity levels were lower at older ages. Younger } \\
\text { children met daily recommendations for physical activity, whereas older children, especially } \\
\text { girls, did not. }\end{array}$ \\
\hline 22. & $\begin{array}{l}\text { Luanna, A.C., } \\
\text { Gerfeson, M., \& } \\
\text { Jose De, F.J. } \\
(2013)\end{array}$ & $\begin{array}{l}\text { A cross-sectional study } \\
\text { (Brazil) }\end{array}$ & 2,361 adolescents & $\begin{array}{l}\text { - Parents and friends have a social influence on adolescents' level of physical activity through } \\
\text { the mechanism of behaviour modelling or through social support }\end{array}$ \\
\hline 23. & $\begin{array}{l}\text { Michelle et al. } \\
(2013)\end{array}$ & $\begin{array}{l}\text { A cross-sectional study } \\
\text { (USA) }\end{array}$ & 1,421 respondents & $\begin{array}{l}\text { - Parent instrumental social support was directly related to girls' PA and parent emotional } \\
\text { social support was inversely related to girls' PA. }\end{array}$ \\
\hline
\end{tabular}




\section{Interpersonal factors that contribute to a decline in physical activity among adolescents}

\section{a. Motivation}

Gredler, Broussard and Garrison (2004) broadly define motivation as "the attribute that moves us to do or not to do something". For this review, PA decline was noticed during young adults' transition into early adulthood, with declines being steepest among men who entered college/ university (Cooper et al. 2012, Taymori et al. 2012). Besides, some studies identified interpersonal characteristics such as personal traits like shyness and anxiety preference to participate in less active play, lack of interest, or lack of ability to follow the rules of organized physical play activities (Graham et al. 2011). Also, lack of motivations towards participation in sport and physical activity were affected by adolescents' perception of their own movement skill ability (Bradley et al. 2011 \& Hsu et al. 2011).

\section{b. Age}

Six (6) of the studies highlighted that age also contributed to decline in PA (Samuel et al, 2011; Bradley et al. 2011; Lammle et al. 2011; Kirby et al. 2011; Marques 2014; Chung et al. 2012). Those studies identified the decline among girls was higher in younger ages at baseline (9-12 years) and it was higher in older ages among boys (13-16 years). In addition, as age increased, the number of participants in team sports activities declined.

With age also, there was a significant decrease in most sports activities among boys and girls. This indicated that as adolescents are getting older, they may have different interests leading some to stop practicing PA. These findings imply that it is important to more effectively promote PA among adolescents, using different strategies based on age and sex (Marques et al. 2014 \& Chen You et al. 2014).

\section{c. Attitude}

Attitude refers to inclinations to react in a certain way to certain situations; to see and interpret events according to certain predispositions, or to organize opinions into coherent and interrelated structures (Ibrahim G. Badran 1995).

PA was both a cause and an outcome of feelings of competence. Among decliners, the relationship between PA and feelings of competence was a barrier to PA. They appeared to compare themselves to peers and negatively evaluate their own skill levels. If you have low self-esteem and you tell yourself you are not good [at a sport] it will complicate things, and you will have less fun, and it will push you to do less exercise, so you will stay home (Belanger et al. 2011).

The girls were less active than boys at both time points. Girls reported lower self-efficacy and perceived more barriers and fewer perceived benefits for physical activity over time (Taymori et al. 2012).

\section{d. Obesity}

Overweight and obesity are defined as abnormal or excessive fat accumulation that presents a risk to health. A body mass index (BMI) over 25 is considered overweight, and over 30 is obese. Rates of overweight and obesity continue to grow in adults and children. From 1975 to 2016, the prevalence of overweight or obese children and adolescents aged 5-19 years increased more than four-fold from 4\% to $18 \%$ globally. (https://www.who.int/health-topics/obesity\#tab=tab_1)

For this review, three prevalent patterns of adolescent obesogenic behaviors were identified and these patterns related to obesity, weight status, depression, and other indicators of physical and psychological health (Charlton 2014; Jaroslava et al.2014; Cheah et al. 2014) Adolescents playing video games 
increased fruit and vegetable consumption by about 0.67 servings per day but not water and moderateto-vigorous PA, or body composition.

\section{e. Social Influences}

Social influence refers to change of attitudes, beliefs, opinions, values and behaviour as a result of being exposed to other individuals' attitudes, beliefs, opinions, values and behaviour. It forms the interface between individualistic and group approaches to social psychology (Hewstone \& Martin 2008)

For this review, support from parent's quality is associated with increased PA in underserved adolescents. The parent's instrumental social support relates greatly to adolescent PA in both underserved boys and girls. Many parents supported a healthy lifestyle through positive role-modeling by making time for personal PA a priority and by participating in active play with their children (Wilson 2011; Michelle S. 2013; Belanger et al. 2011; Hsu et al. 2011).

Nevertheless, a few studies (Luanna et al. 2013; Hylok 2011) cited being single parents, having busy schedules, and feeling fatigued at the end of the day as factors that led them to be less likely to engage in PA with their adolescents. Lack of parental support and parental restrictions also discourage adolescents from participating in structured and free-time physical activity. In other words, parents were the powerful influence of relationships between adolescents and others in their lives in regard to PA.

Adolescents also communicated how role modeling from friends influences how active they are. Active friends' involvement was believed to be important in developing adolescents' knowledge of healthy behaviour including PA. Friends might encourage them to do PA. For example, walking with friends was seen as helpful in increasing the PA levels. But friends were also giving a negative effect by persuading their peers to choose fewer active options like saw movies, screen time(Sawka et al. 2014; Seranno et al. 2011; Hsu et al. 2011; Dudley 2013)

\section{Environmental factors that contribute to a decline in physical activity among adolescents}

\section{a. Neighborhood Environment}

Neighborhood environment is defined as both the physical and social context by which the adolescent is surrounded in their neighborhood (Eric et al. 2013). Neighborhood safety was also commonly cited when identifying factors that may limit adolescents' outdoor playtime. The availability of safe places for activity is important to promote PA for adolescents in urban areas. Their perceptions of safety positively associated with PA among adolescents in low-income neighborhoods. Parents perceived the neighborhood in which they lived to be unsafe, adolescents watched significantly more television and they mentioned that safe places were indoor areas. (Wilson 2011).

\section{b. School Environment}

According to Mick Zais (2011), school environment means the extent to which school settings promote student safety and student health, which may include topics such as the physical plant, the academic environment, available physical and mental health supports and services, and the fairness and adequacy of disciplinary procedures.

School environments provide potential opportunities to increase children's PA levels though there is a need for more methodologically sound interventions to promote PA during school recess with a particular focus on adolescents. The study indicates that mediation of cognitive factors of the physical environment association may not occur when the availability of facilities is considered as the environmental indicator (Hylok 2011). 
School and sports clubs as other important authorities in adolescents PA. The setting offers an important venue for many children to obtain a substantial amount of their daily PA. However, most school children reviewed here did not meet the requirements outline by organizations such as WHO. They also mentioned that many children did not perform in PA, especially in PE because of lack of equipment and these may not meet PA recommendations (Graham et al. 2011; Pabayoa et al. 2011).

The decline in the enjoyment of PA was greatest among girls (regardless of school type) which having to change uniform had the largest negative effect (girls). In addition, strong commitment and a heavy workload at school also impose time constraints (Dudley 2013).

\section{c. Social Environment}

Social environments encompass the immediately physical. surroundings, social relationships, and cultural milieus. within which defined groups of people function and. interact (National Institute of Health 2000).

The home environment is an important setting contributing to the PA behavior of adolescents. Although the home environment is an extremely influential factor in adolescent's level of PA, many studies fall short of examining this environment. (Wilson 2011; Duncan et al. 2012).

Lack of money and a tight budget might be a problem for the adolescent PA. Past studies have shown that younger age, boys, high family socioeconomic status (SES), and household car ownership were associated with more leisure-time PA, moderate-vigorous PA (Baby et al. 2008; Kirby et al. 2013).

The transition between primary to secondary school is associated with a change in travel mode and may affect the overall PA. In addition, motorized transport makes adolescents lazy to do PA. Climate change was also one of the reasons for them not doing PA especially among female students (Joanna et al. 2013; Kwan et al. 2012)

Time was also a concern for some decliners who reportedly discontinued participation in PA because they did not like the time frames (early morning and weekend nights) associated with organized PA. For them, these times generally interfered with their opportunities to take part in social events and other activities. These other activities become increasingly important for some adolescents as they get older. Physical activity can be a low priority compared with social needs (e.g., talking on the phone with friends, spending time with boyfriend/girlfriend) (Kirby et al. 2013; Dudley 2013).

\section{Discussion}

The present scoping review examined the evidence related to the decline in PA among adolescents. In this review, there were two factors that contribute to physical inactivity among adolescents, namely interpersonal and environmental factors. The most contribute variables associated with interpersonal factors were motivation, age, attitude, obesity, and social influence. While the variables related to environmental factors referred to the neighborhood environment, school environment, and social environment.

To our knowledge, there are some issues that should be given consideration in this review, such as, when adolescents grow up, they are more focused on friends and entertainment, rather than doing PA that requires specific time and space to doing so.

Less social support from parents, teachers, family, and friends was among the reasons why they are not motivated to perform PA continuously. Parents are a primary influence on the activity-related behavioral patterns of their children (e.g., sports, outdoor play, and exercise; Beets et al. 2010; Trost \& Loprinzi, 2011). A review by Van der Horst et al. (2007) found that several factors were positively associated with a child's PA, including sex (male), self-efficacy, parental PA (for boys), and parental support. Parental 
practices that involve emotional support have been shown to be positively associated with higher children's PA levels (Gustafson \& Rhodes 2006; Hennessy et al. 2010).

The environment also plays an important role where equipment and facilities are insufficient, a place or setting that is less convenient, and the neighborhood who do not care or conscious activity healthy lifestyle is also a contributing factor to PI. It was also noted that lack of awareness, attitudes, and practices of the individual themselves for not doing PI to maintain a healthy lifestyle.

The diversity of physical activity is also one of the attractions for adolescents to do PA. Costly equipment does not guarantee that they will perform PA, but the fun and practice of healthy living by doing PA with friends, parents, and families is something that needs to be emphasized.

\section{Study Limitation}

Most of the studies relied on self-reported data and cross-sectional study designs with descriptive statistics. To obtain more in-depth information on the predictive factors of participation in physical inactivity, more longitudinal studies are needed. The use of theoretical models and constructs in physical inactivity research was important for understanding behavior change and guiding the development of effective interventions.

\section{Conclusion}

Overall, of the 23 studies reviewed, many variables were found to be significantly associated with physical inactivity. Most of the studies examined variables for which there is already well-established evidence of a positive or negative relationship with physical inactivity.

Special considerations should be made for PA programs specific to these subgroups, such as inactive older adolescents, and low SES adolescents. The modifiable variables identified in this review may be considered potential mediators of adolescents' PA, so interventions should be developed to change these variables through education, family programs, or environmental and policy change.

Therefore, interventions such as including parents in PA programs and encouraging them to support their children's participation in PA and educating parents about the importance of regular PA during childhood and adolescence are needed because parents play important roles in their children's lives and, in consequences, the health of future generations.

\section{Acknowledgement}

The authors would like to express their sincere gratitude and appreciation to the Director-General of Health Malaysia for the permission to publish this report. We would like to thank the Ministry of Health for providing the technical and financial support needed for this study. We would also like to express our appreciation to Dr. Manimaran Krishnan Kaundan, Director of the Institute for Health Behavioural Research, for the support and advice throughout the progress of the study. Also, thanks to the group members that has worked hard in reading and summarizing the previous research article. All the contributions that have been made are highly appreciated.

\section{Ethical Consideration}

The study was registered under the National Medical Research Registry (NMRR 14-332-19589) and the protocol was approved by the Medical Research and Ethics Committee (MREC), Ministry of Health, Malaysia. 


\section{Conflict Of Interest}

The authors declare that they have no conflict interest.

\section{Authors Contributions}

NA, HHA, NJ, NEH, NI, NHAS, SNFH, MRZ, NJ, MHM, SHS carried out literature search and data extraction. NA did data analysis and drafted the manuscript. MK supervisor of the research. All authors read and approved the final manuscript.

\section{References}

Americans Physical Activity Guidelines. (2008). Complements the Dietary Guidelines for Americans. Americans Physical Activity Guidelines Advisory Committee Report, (2008).

Arksey H., \& O'Malley L. (2005). Scoping studies: Towards a methodological framework. International Journal of Social Research Methodology: Theory \& Practice, 8(1): 19-32.

Babey, S.H, Hastert, T.A., Yu, H., \& Brown, E.R. (2008). Physical activity among adolescents. When do parks matter? Am J Prev Med. 34(4):345-348.

Beets, M.W, Cardinal, B.J., \& Alderman, B.L. (2010). Parental social support and the physical activityrelated behaviors of youth: A review. Health Education \& Behavior, 37(5): 621-644.

Belanger, M., Casey, M., Cormie,r M,, Filion, A.L, Martin, G., Aubut, S., Chouinard, P., Savoie, S.P., \& Beauchamp, J. (2011). Maintenance and decline of physical activity during adolescence: insights from a qualitative study. Int J Behav Nutr Phys Act. 8:117.

Bradley, R.H., McRitchie, S., Houts, R.M., Nader, P., \& O'Brien, M. (2011). Parenting and the decline of physical activity from age 9 to 15. International Journal of Behavioral Nutrition and Physical Activity, 8:33.

Booth, F., \& Chakravarthy, M. (2002). Cost and consequences of sedentary living: New battleground for an old enemy. (2002). Washington, DC: President's Council on Physical Fitness and Sports Research Digest.

Bull, F.C., Armstrong, T, P., Dixon, T., Ham, S., Neiman, A., \& Pratt, M. (2004). Physical Inactivity : $730-854$.

Charlton, R., Gravenor, M.B., Rees, A., Knox, G., Hill, R., Rahman, M.A., Jones, K., Christian, D., Baker., J.S., Stratton, G., \& Brophy, S. (2014). Factors associated with low fitness in adolescents - A mixed methods study. BMC Public Health, 14:764.

Cheah, L.W., Helmy, H., \& Chang, C.T. (2014). factors associated with physical inactivity among female and male rural adolescents in Borneo-a cross sectional study. Int J Adolesc Med Health, $1-7$.

Chen, Y, Zheng, Z, Yi, J., \& Yao, S. (2014). Associations between physical inactivity and sedentary behaviors among adolescents in 10 cities in China. BMC Public Health 14 (744) : 1-9.

Chung, A.E., Skinner, A.C., Steiner, M.J., \& Perrin, E.M. 2012. Physical Activity and BMI in a Nationally Representative Sample of Children and Adolescents. Clinical Pediatrics 51(2):122129. https://doi.org/10.1177/0009922811417291

Colditz G,A. (1999). Economic costs of obesity and inactivity. Med Sci Sports Exerc ,31: S663-S667.

Cooper, A.R., Jago, R., Southward, E.F., \& Page, A.S. (2012). Active travel and physical activity across the school transition: the PEACH project. Med Sci Sports Exerc, 44(10):1890-1897

Dudley, D.A., Okely, A.D., Pearson, P., Cotto, W.G., \& Caputi, P. (2012). Changes in physical activity levels, lesson context, and teacher interaction during physical education in culturally and linguistically diverse Australian schools. International Journal of Behavioral Nutrition and Physical Activity, 9 (1), 1-9.

Dumith, S.C., Gigante, D.P., Domingues, M.R., \& Kohl, H.W. (2011). Physical activity change during adolescence: a systematic review and a pooled analysis. Int J Epidemiol, 40(3):685-698. 
Graham, D.J., Schneider, M., \& Dickerson, S.S. (2011). Environmental resources moderate the relationship between social support and school sports participation among adolescents: a crosssectional analysis. International Journal of Behavioral Nutrition and Physical Activity, 8:34.

Gredler, M.E., Broussard, S.C., \& Garrison, M.E.B. (2004) The Relationship between Classroom Motivation and Academic Achievement in Elementary School Aged Children. Family and Consumer Sciences Research Journal, 33, 106-120. https://doi.org/10.1177/1077727X04269573

Gustafson, S.L., \& Rhodes, R.E. (2006). Parental correlates of physical activity in children and early adolescents. Sports Medicine (Auckland, N.Z.), 36(1): 79-97.

Gyurcsik, N.C., Bray, S.R., \& Brittain, D.R. (2004). Coping with barriers with physical activity during transition to university. Family and community health. 27(2):130-142.

Hallal, P.C., Victora, C.G., \& Azevedo, M.R. (2006) Adolescent physical activity and health: a systematic review. Sports Med 36, 1019-1030.

Hennessy, E., Hughes, S.O., Goldberg, J.P., Hyatt, R.R., \& Economos, C.D. (2010). Parent-child interactions and objectively measured child physical activity: A Crosssectional study. The International Journal of Behavioral Nutrition and Physical Activity, 7(1): 71.

Hewstone, M., \& Martin, R. (2008). Social influence. In M. Hewstone, W. Ströbe, \& K. Jonas (Eds.), Introduction to social psychology: a European perspective (4th ed ed., pp. 216-243). (BPS textbooks in psychology). Blackwell.

Holly, C., Salmond, S., \& Saimbert, M.K. (2011). Comprehensive Systematic Review for Advanced Nursing Practice. NY: Springer Publishing.

Hsu, Y.W., Chou, C.P., Nguyen-Rodriguez, S.T., McClain, A.D., Belcher, B.R., \& Spruijt-Metz, D. 2011. Influences of Social Support, Perceived Barriers and Negative Meanings of Physical Activity on Physical Activity in Middle School Students. J Phys Act Health, 8(2):210-219.

Hylok, M.J. (2011). Exploring student perceptions to explain the relationship between physical activity and academic achievement in adolescents: a mixed methods study: http://digitalcommons.unl.edu/cehsdiss/99. Health Education Research, 28 (6):954-969.

Ibrahim, G. Badran. 1995. Knowledge, attitude and practice the three pillars of excellence and wisdom: a place in the medical profession. Eastern Mediterranean Health Journal 1(1):8-16.

Jaroslava, K., Zuzana, D.V., Andrea, M.G., Jitse, P.Van Dijk., Sijmen, A.R. (2014). Is Being A Boy and Feeling Fat A Barrier for Physical Activity? The Association Between Body Image, Gender and Physical Activity Among Adolescents. Int J Environ Res Public Health.11(11): 11167-11176.

Katzmarzyk, P.T., Gledhill, N. \& Shephard, R,J. (2000). The economic burden of physical inactivity in Canada. CMAJ,163:1435-40.

Kirby, J., Levin, K.A., \& Inchley, J. (2013). Socio-environmental influences on physical activity among young people: a qualitative study. Health Education Research, 28(6): 954-969, https://doi.org/10.1093/her/cyt085

Kwan, M.Y., Cairney, J., Faulkner, G.E. \& Pullenayegum, E,E. (2012). Physical activity and other health-risk behaviors during the transition into early adulthood: a longitudinal cohort study. Am J Prev Med, 42(1): 14-20.

Lammle, L., Worth, A., \& Bos K. (2012). Socio-demographic correlates of physical activity and physical fitness in German children and adolescents. Eur J Public Health, 22(6):880-884.

Lee, I.M,. \& Skerrett, P.J. (2001) : Physical activity and all-cause mortality: what is the dose-response . (6 Suppl):S459-71; discussion S493-School of Public Health, Boston, MA 02215, USA

Luanna, A.C., Gerfeson, M., \& Jose De, F.J. (2013). Physical activity in adolescents: analysis of the social influence of parents and friends. J Pediatr (Rio J). 90(1):35-41.

Malaysian Dietary Guidelines. (2010). Ministry of Health Malaysia.

Marques, A., \& Matos, M.G. (2014). Adolescents' physical activity trends over the years: a three-cohort study based on the Health Behaviour in School-aged Children (HBSC) Portuguese survey. BMJ Open. 4(9): e006012.

McLean, G., \& Teague, M. (2004). Obstacle to action: A study of New Zealanders Physical Activity and Nutrition: Qualitative Phase, Australians Journal of Parks and leisure.

Michelle, S.P., Hannah, G.L., Amanda, F.D., Wilson, K., \& Lee, V.H. (2013). The Association of SelfEfficacy and Parent Social Support on Physical Activity in Male and Female Adolescents. Health Psychol. 32(6): 666-674. 
Mick, Z. (2011). South Carolina School Environment Initiative. South Carolina Department of Education, Columbia. Retrieved on March 21, 2012, from http://ed.sc.gov/agency/ac/StudentInterventionServices/documents/SC-SchoolEnvironmentRFP-Nov2011.pdf

National Institutes of Health. Health Disparities: Linking Biological and Behavioral Mechanisms with Social and Physical Environments. Bethesda, Md: National Institutes of Health; 2000. RFA ES00-004.

Reilly, J.J. (2005). Descriptive epidemiology and health consequences of childhood obesity. Best practice \& research. Clinical Endocrinology \& Metabolism, 19, 327-341.

Romanow, R.J. (2002). Building on Values: The Future of Health Care in Canada. Ottawa, ON: Commission on the Future of Health Care in Canada.

Serrano-Sanchez, J.A., Marti'-Trujillo, S., Lera-Navarro, A., Dorado-Garci'a, C., Gonza'lezHenri'quez, J.J., et al. (2011) Associations between Screen Time and Physical Activity among Spanish Adolescents. PLoS ONE 6(9): e24453. doi:10.1371/journal.pone.0024453

Sawka, K.J, Gavin, R.M., Alberto, N.A., Anita, B., Rosemarry, P., \& Penelope, H. (2014). Associations between aspects of friendship networks, physical activity and sedentary behaviour among adolescents. Journal of Obesity: 1-12.

Taymoori, P., Berry, T.R., \& Lubans, D.R. (2012). Tracking of physical activity during middle school transition in Iranian adolescents. Health Education Journal, 71(6):631-641.

Taras, H., \& Potts-Datema, W. (2005). Obesity and student performance at school. J Sch Health, 75(8):291-5.

Teng Y-K, Huang J-L, Yeh K-W, Fu L-S, Lin C-H, Ma W-F, et al. (2014) Influential Factors of Insufficient Physical Activity among Adolescents with Asthma in Taiwan. PLoS ONE 9(12): el 16417. https://doi.org/10.1371/journal.pone.0116417

Telama, R., Yang, X., \& Viikari, J. (2005) Physical activity from childhood to adulthood: a 21-year tracking study. Am J Prev Med 28: 267-273.

Trost, S.G., \& Loprinzi, P.D. (2011). Parental influences on physical activity behavior in children and adolescents: A brief review. American Journal of Lifestyle Medicine, 5(2):171-181.

UN-habitat. 2003. Planning and design for sustainable urban mobility: global report on human settlements 2013. Oxford, United Kingdom of Great Britain and Northern Ireland: United Nations Human Settlements Programme. (https://unhabitat.org/planning-anddesign-for-sustainableurban-mobility-global-reporton-human-settlements-2013/)

(https://www.cdc.gov/chronicdisease/resources/publications/factsheets/physical-ctivity.htm).

US Department of Health and Human Services (2008). Physical Activity Guidelines Advisory Committee Report 2008. Washington, DC: DHHS.

Van der Horst, K., Kremers, S., Ferreira, I., Singh, A., Oenema, A., \& Brug, J. (2007). Perceived parenting style and practices and the consumption of sugar-sweetened beverages by adolescents. Health Education Research, 22(2):295-304.

Wilson, D.K., Lawman, H.G., Segal, M., \& Chappell, S. (2011). Neighbourhood And Parental Supports for Physical Activity in Minority Adolescent. Am J Prev Med. 41(4):399-406.

WHO. (2008). Physical Inactivity: A Global Public Health problem. https://www.who.int/dietphysicalactivity/factsheet_inactivity/en/[retrieved 10 July 2014].

WHO. (2014). Physical Activity. https://www.who.int/health-topics/physical-activity\#tab=tab_108012021(retrieved 8 July, 2014)

WHO. (2014). Obesity. https://www.who.int/health-topics/obesity\#tab=tab_1(retrieved 8 July, 2014) 